\title{
Smoking cessation study receives major award
}

\author{
A large collaboration led by Dr Richard \\ Holliday (pictured) and Professor Elaine \\ McColl from Newcastle University has \\ received a major funding award from the \\ National Institute for Health Research \\ (NIHR). \\ The ENHANCE-D Study (ENHANCing \\ smoking cEssation interventions in \\ Dentistry) has been awarded combined \\ research and NHS costs of $£ 2.8$ million. The \\ study will evaluate the impact of primary \\ care dental professionals providing 'in house' \\ enhanced smoking cessation interventions \\ such as nicotine replacement therapy (NRT) \\ or e-cigarettes on both quit rates and oral \\ health parameters. \\ The study was designed through a \\ co-production approach which involved \\ a wide range of dental professionals and \\ patients. The study plans to recruit 1,460 \\ participants across 56 dental practices in \\ seven research regions (Newcastle, Dundee, \\ Sheffield, Birmingham, Glasgow, Edinburgh \\ and Plymouth). Each dental practice will
}

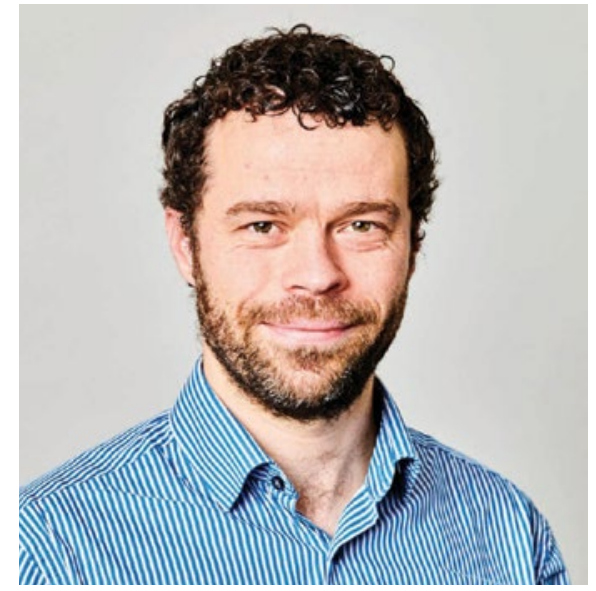

Dr Richard Holliday, who is leading the ENHANCE-D Study with Professor Elaine McColl

identify two staff members (any member of the dental team) to receive training on the interventions and will be reimbursed for taking part in the research. Novel to this trial will be the use of dental therapists and dental hygienists as principal investigators ('leads') at some dental practices. Participant recruitment is anticipated to start in the second half of 2021 and the study will run for four years.
Additionally, biological samples (plaque and epithelial cells) will be collected for future analysis and an economic and qualitative evaluation will be completed.

Research hubs: Newcastle (Dr Richard Holliday), Dundee (Prof. Jan Clarkson), Sheffield (Prof. Zoe Marshman and Dr Claire Storey), Birmingham (Dr Praveen Sharma), Glasgow (Dr Shauna Culshaw and Prof. David Conway), Edinburgh (Prof. Angus Walls) and Plymouth (Mr Timothy O’Brien).

For information on the study visit: https://www.journalslibrary.nihr.ac.uk/ programmes/hta/NIHR129780. To express an interest in taking part visit: https://blogs. ncl.ac.uk/northerndentres/currentprojects/ enhance-d-study-expression-of-interest/.

This study is funded by the National Institute for Health Research (NIHR) [Health Technology Assessment (NIHR129780)]. The views expressed are those of the author(s) and not necessarily those of the NIHR or the Department of Health and Social Care.

\section{BFS bolstered by high profile advocates}

The British Fluoridation Society (BFS) is delighted that two highly experienced advocates for community water fluoridation (CWF) are now working with the Society. Alan Johnson, former Labour MP and a Secretary of State for Health, is a Vice President and Barry Cockcroft, the former Chief Dental Officer for England, has joined the BFS Council.

The Chair of BFS, Steve Bedser, said: 'Alan joins a long line of high profile social justice campaigners who have added their name to a BFS Vice President role. Both Alan and Barry have a great record as water fluoridation advocates. I am confident that both will be great assets to the society?

British politician Alan Johnson was for 20 years the Labour MP for Hull West and Hessle where he actively supported the proposal to introduce water fluoridation. The oral health of children in this area is among the worst in England, making water fluoridation a 'no brainer, he said. No longer an MP, he remains a champion of targeted water fluoridation both in Hull and nationally.

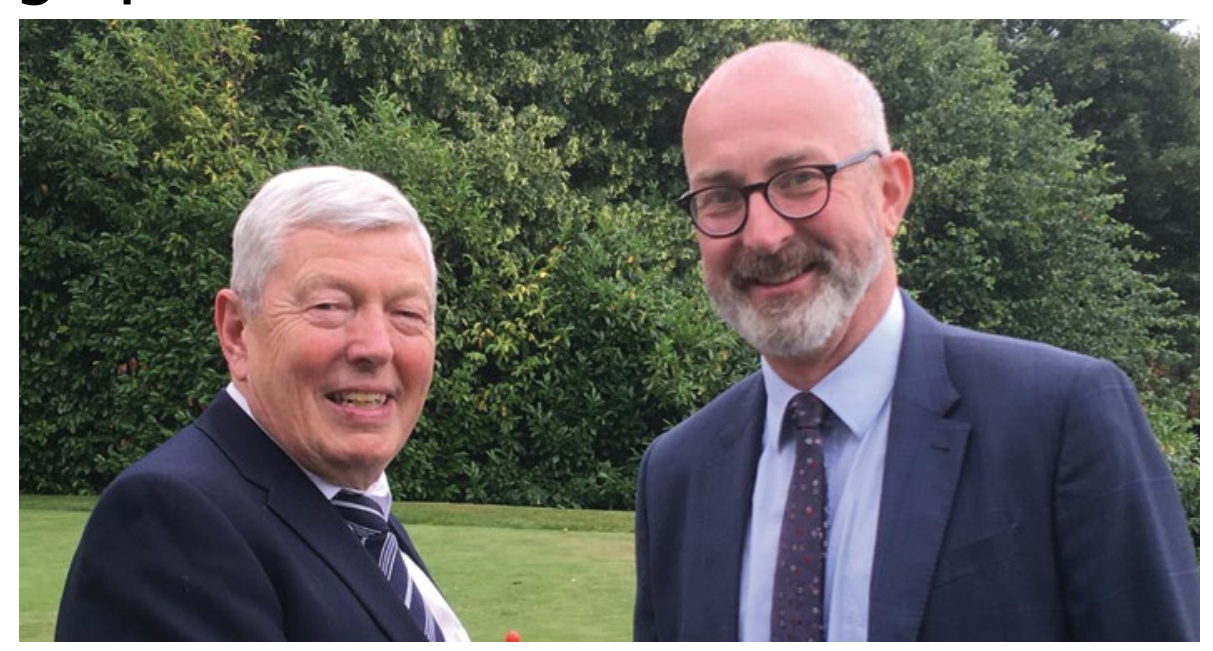

Alan Johnson and Steve Bedser

Barry worked tirelessly to introduce water fluoridation in Southampton while CDO (2005-2015). Supported by the BFS, the BDA and many other organisations, his impeccable campaign was ultimately successful at judicial review. Regrettably, the scheme was not implemented because new legislation - the Health and Social Care Act 2012 - was introduced at a critical juncture and abolished Strategic Health Authorities, consigning this important victory to history.

Of his new role on the Council of BFS, Barry said: 'I have always been a fan of water fluoridation and being on the BFS Council is a great opportunity to help move forward on this invaluable preventative measure'. 